\title{
NIHR Open Access Policy Review Stakeholder Survey Results
}

Authors: Alex Recio-Saucedo (alejandra.recio-saucedo@nihr.ac.uk) and Katie Meadmore (katie.meadmore@nihr.ac.uk).

\section{Introduction}

Open Access (OA) publishing makes academic peer-reviewed research freely available online for anyone to read and reuse. The Government's Research and Development Roadmap sets out a commitment to "require that research outputs funded by the UK government are freely available to the taxpayer who funds research". In Autumn of 2020, the Department of Health and Social Care (DHSC) ran a consultation to inform the review of the National Institute for Health Research (NIHR) OA Policy. The survey focussed on opportunities and barriers of OA, views on the existing NIHR OA policy and gathered specific feedback on proposed policy options (Annex A). The DHSC was interested in capturing a diversity of views from individuals and organisations both funded and not funded by the NIHR. This report presents the findings of the survey responses, which have played a key part in shaping the revised NIHR OA policy. Thank you to all 414 respondents who have taken the time to provide us with their views and perspective on OA publishing and policies.

\section{Methodology}

Development and design: A cross-sectional online survey design was used to gather quantitative and qualitative information about stakeholder opinions on opportunities and barriers of OA, the current NIHR OA policy and the proposed NIHR OA policy. The survey, developed in Google Forms, used closed, tick-box questions and open (free-text) questions. The survey was developed by the cross-NIHR OA working group and refined through an iterative process and in consultation with a broad range of internal (NIHR) and external stakeholders. These groups also tested the face validity of questions, in particular, language, comprehension and completion time, and the construct validity of the questions and response options. The final survey consisted of 52 open and closed questions, and respondents were only presented with questions that were applicable to them.

Survey delivery: The survey was launched on the 29th of September 2020 and was delivered online to have a broad reach. It was open for 6 weeks on the NIHR official website and was promoted using the NIHR website, relevant social media channels, existing NIHR public partnership communities/networks and during two public contributor workshops run by the DHSC in October 2020. The survey was open without restrictions.

Analysis: Descriptives (percentage frequencies and numbers) were provided for closed questions. Open questions were analysed using thematic analysis. To do this, data were coded into meaningful codes by two researchers, and were then grouped into high-order themes through an iterative process. Whole responses and part responses could be coded to more than one theme or subtheme. Higher level concepts are reported in this paper.

\section{Demographics of respondents}

There were four overarching pathways through which the respondents could navigate the survey that depended on their NIHR funding demographics (see Table 3.1); respondents could have filled out the survey as an individual or on behalf of an organisation and either be 
currently or previously supported by the NIHR, or not. More responses were filled out by individuals than organisations ( $\mathrm{N}=382 / 414,92 \%)$, and more individuals were currently or previously funded/supported by the NIHR ( $\mathrm{N}=266 / 382,64 \%)$ than not. Respondents who were currently or previously funded/supported by the NIHR included NIHR Academy award holders, NIHR research programme award holders and/or NIHR funded infrastructure and were in a variety of research areas and career stages (see Figures 3.1-3.3). Organisations and individuals who were not funded/supported by NIHR also came from a range of sectors (see Figure 3.4).

Table 3.1. Demographics of survey respondents

\begin{tabular}{|l|l|l|l|}
\cline { 2 - 4 } \multicolumn{1}{c|}{} & Total & $\begin{array}{l}\text { Filled out on behalf } \\
\text { of an organisation }\end{array}$ & $\begin{array}{l}\text { Filled out by an } \\
\text { individual }\end{array}$ \\
\hline $\begin{array}{l}\text { Currently or previously } \\
\text { funded/supported by } \\
\text { the NIHR }\end{array}$ & $\begin{array}{l}\mathrm{N}=283(68 \%) \\
\text { (See Figure 1a, 1b } \\
\text { and 2) }\end{array}$ & $\mathrm{N}=17(4 \%)$ & $\begin{array}{l}\mathrm{N}=266(64 \%) \\
\text { (see Figure 3 for } \\
\text { stage of career) }\end{array}$ \\
\hline $\begin{array}{l}\text { Not currently or } \\
\text { previously } \\
\text { funded/supported by } \\
\text { the NIHR }\end{array}$ & $\begin{array}{l}\mathrm{N}=131(32 \%) \\
(\text { see Figure 4) }\end{array}$ & $\mathrm{N}=15(4 \%)$ & $\mathrm{N}=116(28 \%)$ \\
\hline Total & $\mathrm{N}=414(100 \%)$ & $\mathrm{N}=32(8 \%)$ & $\mathrm{N}=382(92 \%)$ \\
\hline
\end{tabular}

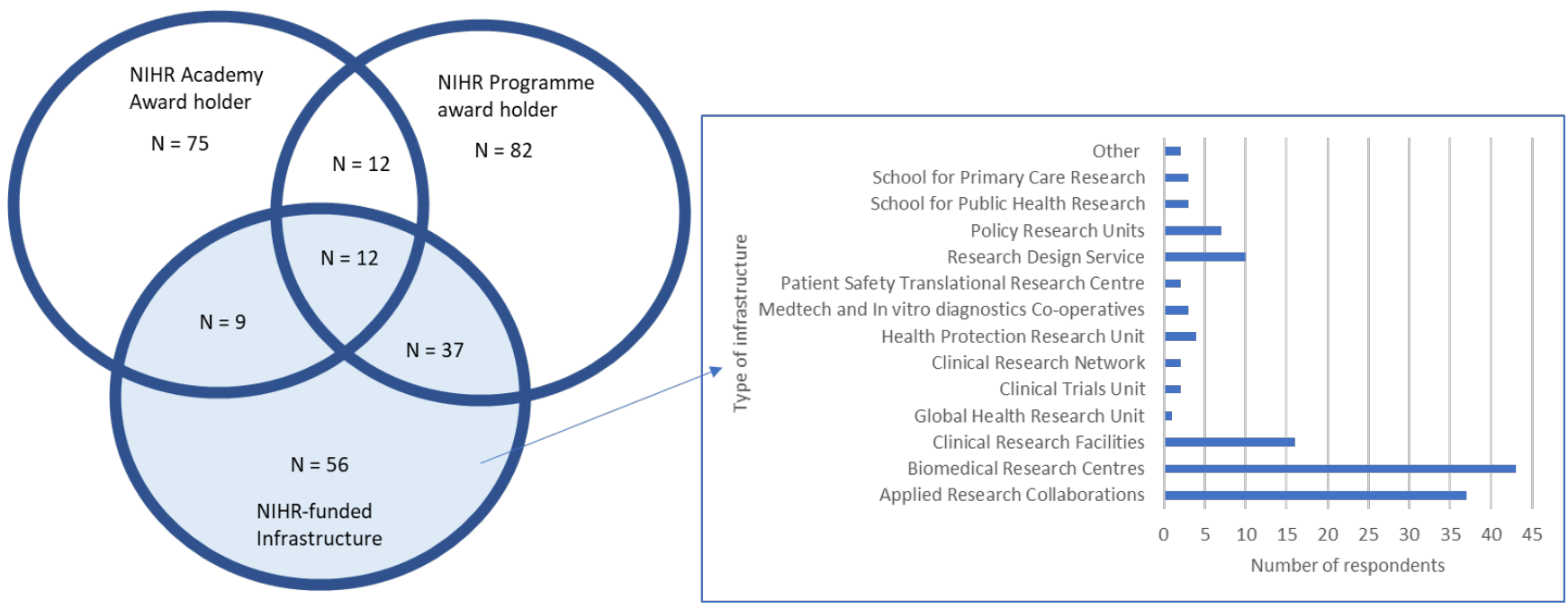

(a)

(b)

Figure 3.1a. Venn diagram to show how respondents (individuals or organisations) are currently or previously funded/supported by the NIHR $(\mathrm{N}=283)$. Note respondents could select more than one area of funding/support.

Figure 3.1b. The type of NIHR-infrastructure that is supporting/funding respondents $(\mathrm{N}=114)$. Note respondents could select more than one area of infrastructure. 


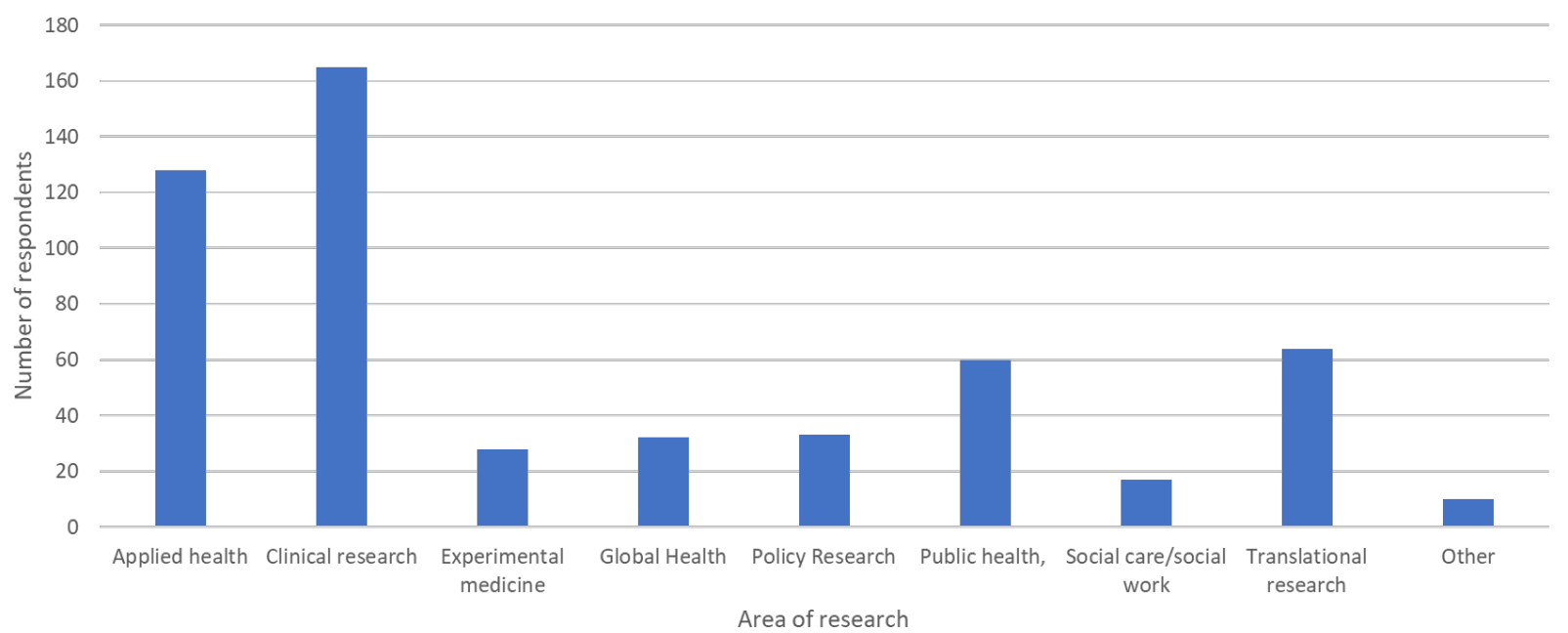

Figure 3.2. The area of research of respondents who filled out the survey as an individual or organisation and are currently or previously funded/supported by the NIHR $(\mathrm{N}=283)$. Note respondents could select more than one area of research.

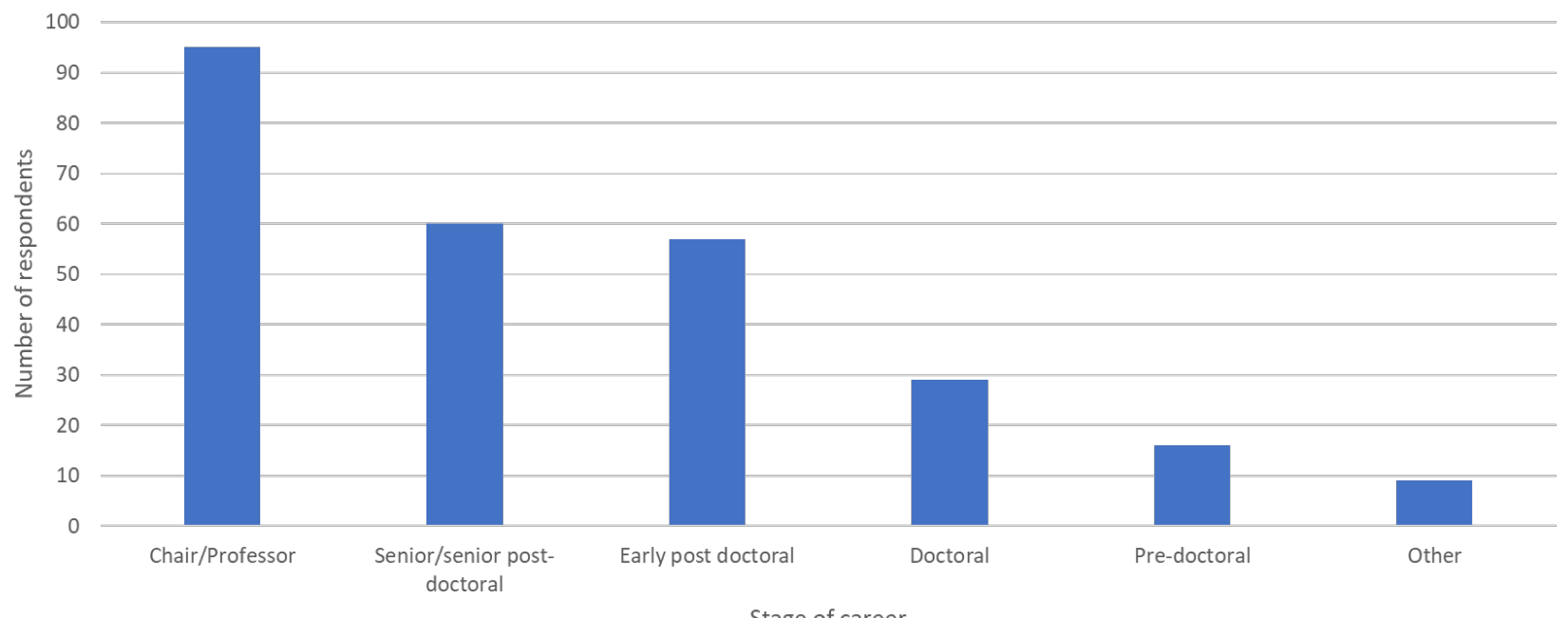

Figure 3.3. Career stage of individual respondents who are currently or previously funded/supported by the NIHR $(\mathrm{N}=266)$. 


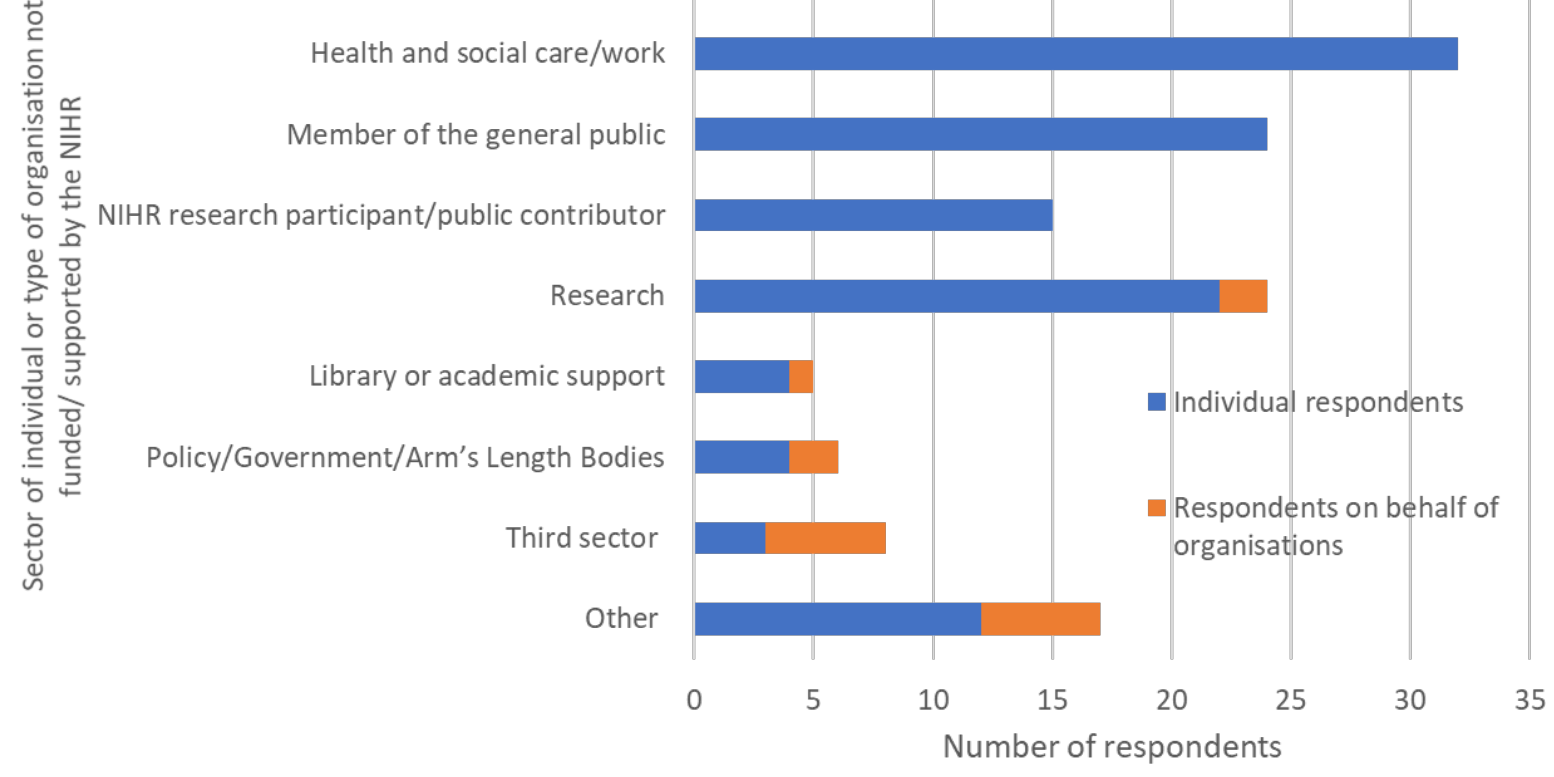

Figure 3.4. Sector of individual or type of organisation not currently or previously funded/supported by the NIHR $(\mathrm{N}=131)$.

\section{Views on future NIHR OA Policy}

This section reports responses on views of future NIHR OA policy from all 414 respondents.

\section{Scope of the OA policy}

Respondents were asked about the proposed scope of the NIHR OA policy.

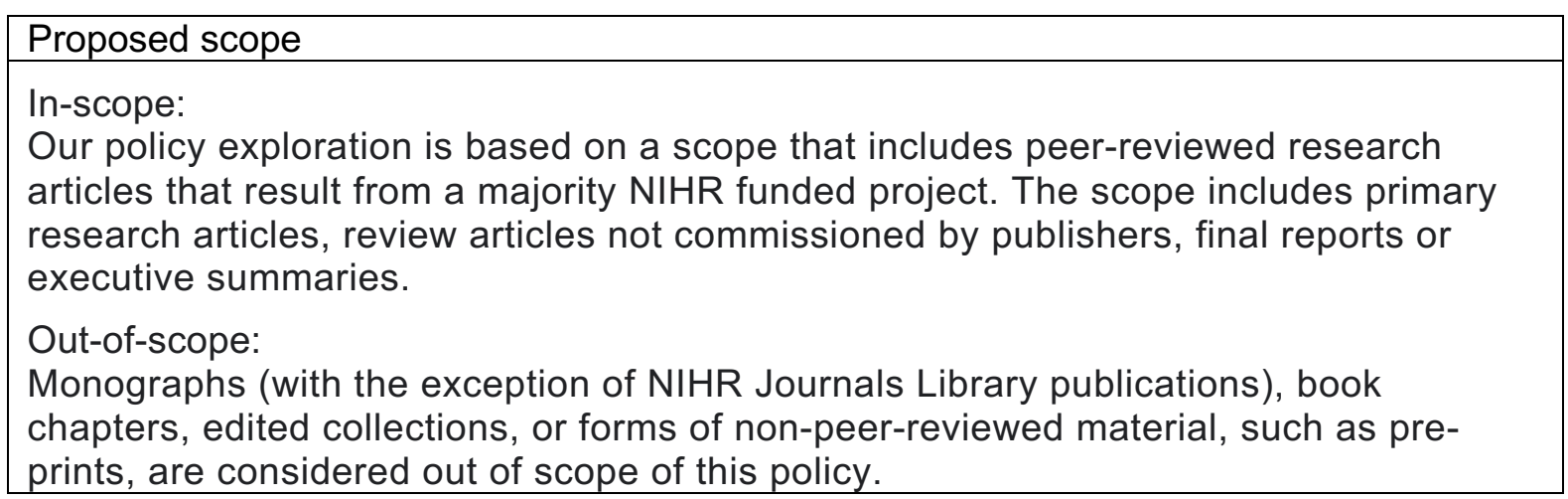

The survey showed that, in general, respondents agreed that the proposed scope for the NIHR OA policy was clear and appropriate (see Table 4.1), although responses ranged from strongly agree to strongly disagree. Comments showed that respondents agreed with the principles of $\mathrm{OA}$ and some respondents were in full agreement with the policy. However, there were also comments on the need for further clarity of the scope, especially with regards to majority funding and publications reporting non-primary outcomes. In addition, whilst some respondents suggested extensions to the policy scope to include other publications such as pre-prints, chapters, or articles in professional publications, other respondents suggested that the policy be restricted to include only peer-reviewed 
publications as proposed. There were also comments around whether there were sufficient funds to meet publication expectation.

Table 4.1. Views on proposed policy scope.

\begin{tabular}{|l|l|l|l|l|}
\cline { 2 - 5 } \multicolumn{1}{c|}{} & Mean & Median & Min $^{*}$ & Max $^{*}$ \\
\hline $\begin{array}{l}\text { The proposed scope is clear. } \\
\mathrm{N}=414\end{array}$ & 4.08 & 4 & 1 & 5 \\
\hline $\begin{array}{l}\text { The proposed scope is } \\
\text { appropriate. } \mathrm{N}=414\end{array}$ & 3.96 & 4 & 1 & 5 \\
\hline
\end{tabular}

*1 = strongly disagree, 5 = strongly agree

When respondents were asked whether the NIHR should introduce restrictions on the types of OA publishing that its funds can be used to support, $49 \%(\mathrm{~N}=202 / 414)$ of respondents agreed (see Figure 4.1). However, 21\% ( $\mathrm{N}=86 / 414)$ of respondents disagree that there should be restrictions and $23 \%(\mathrm{~N}=97 / 414)$ responded don't know.

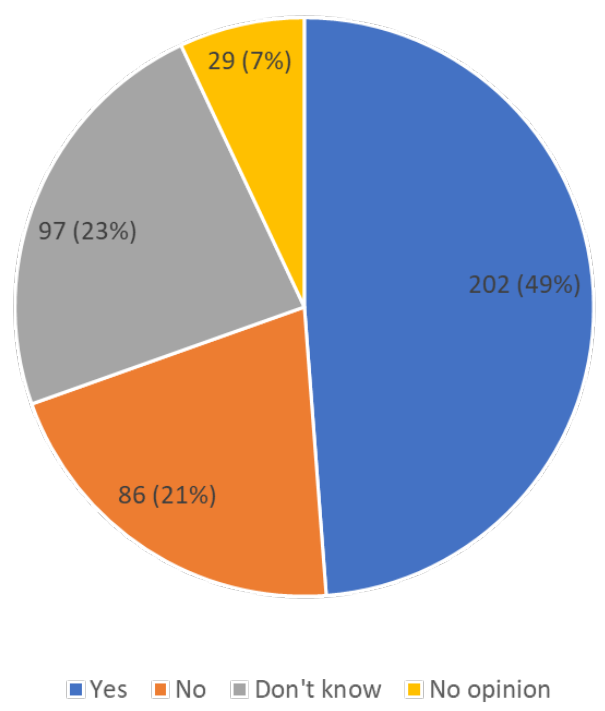

Figure 4.1. Views on whether NIHR should introduce restrictions on the types of OA publishing that its funds can be used to support.

\section{Implementation date of the OA policy}

The survey consulted on the proposal that the revised NIHR OA policy will apply to NIHR awards which begin on or after 1 April 2022. Overall, 53\% ( $N=218 / 414)$ of respondents agreed with the proposed implementation date, although $28 \%(\mathrm{~N}=114 / 414)$ believed it should be earlier (see Figure 4.2). Comments generally reflected that the policy should either be implemented as soon as possible and without delay, or that there should be a delay to consider the need to increase knowledge on OA and the proposed policy before implementing the new policy. 


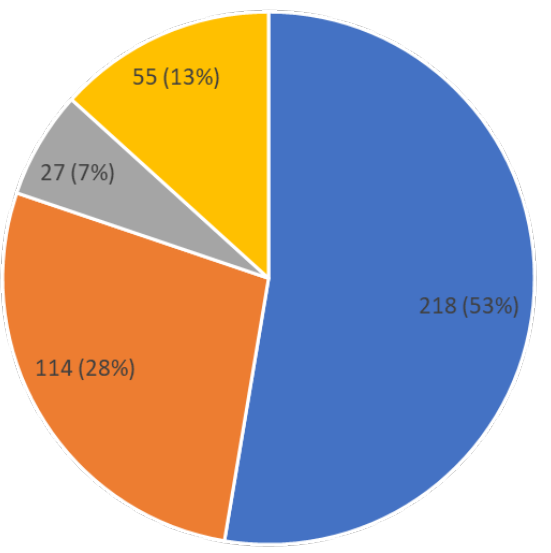

- I agree with the proposed implementation date

- The implementation date should be earlier than the proposed date

- The implementation date should be later than the proposed date

므 No opinion

Figure 4.2. Respondents' views about the implementation date of the proposed policy.

\section{Self-Archiving}

Respondents were asked whether they agree or disagree that, where all of the policy's criteria are met, self-archiving of the Author's Accepted Manuscript (AAM) in an online repository is an acceptable route to achieve OA. The AAM is the author's final, peerreviewed and corrected manuscript which incorporates any amendments based on the peerreviewers' feedback, but before copy editing and typesetting by the publisher. Overall, 64\% $(\mathrm{N}=285 / 414)$ of respondents agree that self-archiving of the AAM in a repository is an acceptable route to achieve OA (see Figure 4.3a). In addition, respondents were asked whether they agreed or disagreed that NIHR should mandate the use of the repository Europe PMC (rather than an institutional, or other subject specific, repository) for achieving OA through self-archiving. Responses showed that the majority agree $(39 \%, N=162 / 414)$ that the NIHR should mandate the use of Europe PMC. $21 \%(\mathrm{~N}=88 / 414)$ disagreed with this proposal and 26\% ( $N=106 / 414)$ responded 'don't know' (see Figure 4.3b). (See also Figures 6.3 and 6.4 and relevant text on pages $17-18$ for some of the reasons reported by participants for not using Europe PMC). 


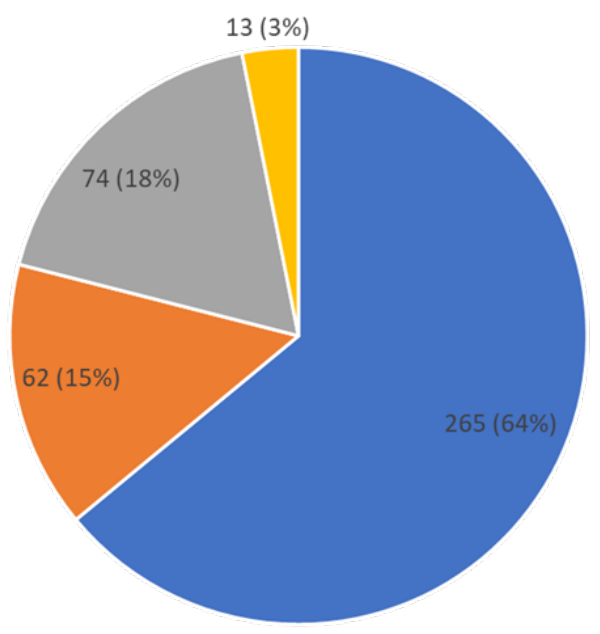

(a) $\square$ Agree $\square$ Disagree $=$ Don't know $\square$ No opinion

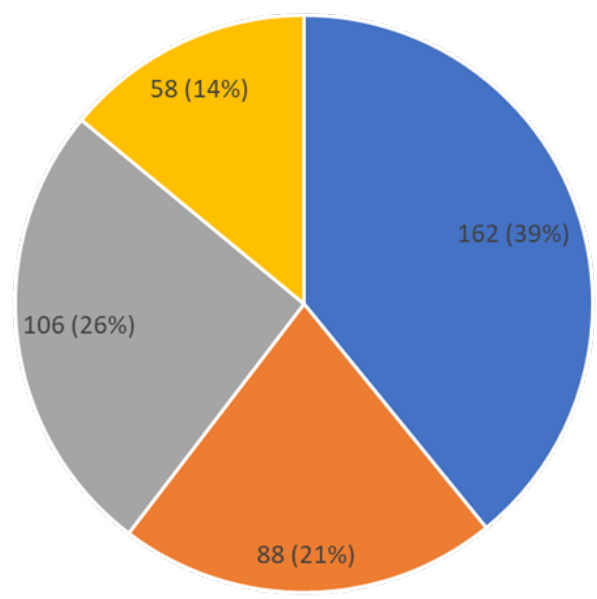

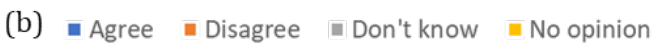

Figure 4.3 Respondents views on whether (a) self-archiving of the author's accepted manuscript in a repository is an acceptable route to achieve OA and (b) the NIHR should mandate the use of Europe PMC for achieving OA through self-archiving.

\section{Copyright licencing and retention}

With regards to copyright licencing, respondents were asked if they were aware of any situations where publication of NIHR research would warrant exceptional use of a 'CC BYND' non-derivative licence. CC-BY-ND refers to a liberal Creative Commons licence which allows anyone to read and share the original material for free, with appropriate credit, but restriction that if the reader adapts the original material, they may not distribute the adapted material. Only $5 \%$ of respondents know of a situation where publication of NIHR research would warrant exceptional use of a CC-BY-ND licence (see Figure 4.4). Some respondents provided examples of exceptional use of the CC-BY-ND licence which included protecting or avoiding misuse, the development of clinical assessment instruments or tools and collaborations with industry. Respondents also indicated a need for better understanding of the types of licenses available. 


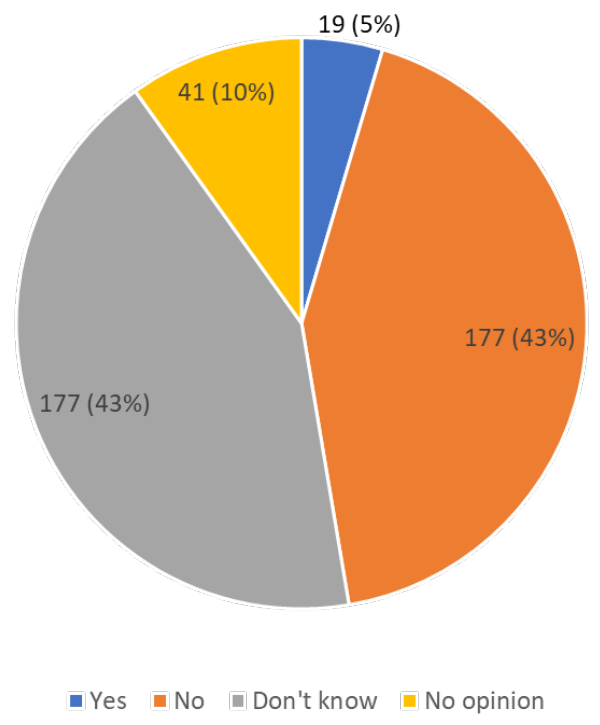

Figure 4.4. Respondents' awareness of any situations where publication of NIHR research would warrant exceptional use of a CC-BY-ND licence.

Respondents were also asked whether they agree or disagree that NIHR should require authors (or their institutions) to retain copyright for in-scope research articles. Retaining copyright means that authors or their institutions are in control of the licence which applies to the article, rather than the publisher.

The survey showed that $51 \%(\mathrm{~N}=211 / 414)$ of respondents agree that NIHR should require authors (or their institutions) to retain copyright for in-scope research articles, however, $31 \%$ $(\mathrm{N}=128 / 414)$ responded 'don't know' (see Figure 4.5). The reasons provided by respondents as to why copyright should be retained by the author or institution included authors being able to reuse work for other purposes and enabling clinical assessments and publicly funded work to be freely available. Some respondents also suggested that NIHR, as the funder, should hold all or joint rights, although others indicated that the funder should be involved very minimally, if at all. Concerns were raised about how to tackle copyright breaches or commercial exploitation (commercial organisations getting the rights and blocking dissemination) and impacts on collaborations and publication. The role of the publisher was raised, with respondents being concerned whether publishers would agree to authors retaining rights and whether this would restrict where findings could be published. Some comments showed lack of understanding of copyright and the implications of retaining rights. 


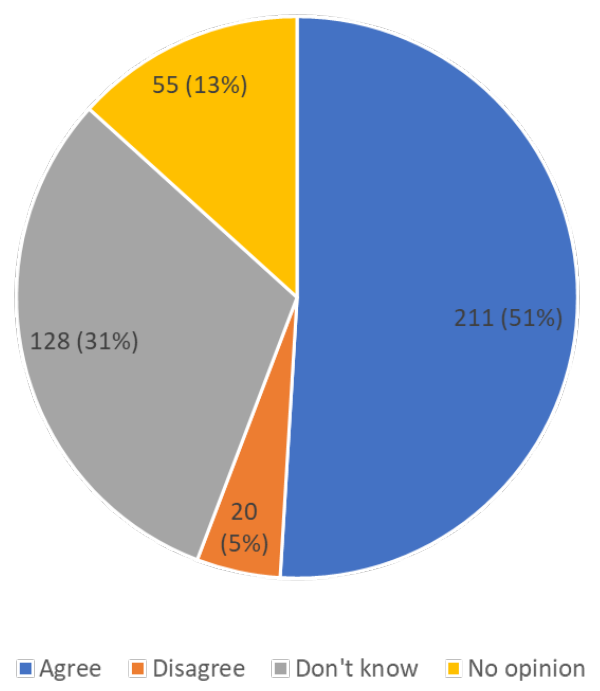

Figure 4.5. Respondents' views on whether NIHR should require authors (or their institutions) to retain copyright for in-scope research articles.

\section{Impacts of the OA policy}

Respondents were asked what impact on them (or the organisation / community they represent) they foresee as a result of our proposed policy principles (Annex $A$ ). The survey showed that overall respondents foresee positive $(38 \%, \mathrm{~N}=157 / 414)$ or positive and negative (34\%, $N=139 / 414$ ) impacts as a result of the proposed policy principles. In addition, $6 \%$ $(\mathrm{N}=26 / 414)$ of respondents indicated the policy would have no impact and only $2 \%$ $(\mathrm{N}=9 / 414)$ believed there would be only negative impact. $20 \%(\mathrm{~N}=83 / 414)$ did not know or had no opinion. A higher proportion of respondents (individuals and organisations) not currently or previously funded/supported by the NIHR reported only positive impacts (58\%, $\mathrm{N}=76 / 116$ ) compared to respondents currently or previously funded/supported by the NIHR and filled out by an individual $(29 \%, \mathrm{~N}=81 / 283)$ (see Table 4.2 ).

Comments suggested that respondents saw the policy as a way to change research culture with regards to publishing $O A$ and increasing accessibility of research for all. Furthermore, respondents reflected that increased accessibility would increase uptake of findings and allow for more transparency in research.

By contrast, some respondents indicated that the OA policy might restrict in which journals research can be published, affecting researcher choice. In addition, whilst some respondents were positive about NIHR covering all publication costs, others raised concerns over whether all costs could be sustainably met and the implications if publishers increased the charges to publish articles OA. Other negative impacts were raised around potential conflicts for the researchers due to varying funders versus publishers policies on licensing and embargos, as well as potential tensions between OA publishing and institutional repositories (especially where universities have invested in these). There was also some concern over additional administrative burden for researchers and duplication of effort where different policies would require articles to be deposited in multiple repositories.

Those respondents who indicated the policy would have no impact or that they didn't know, reported that they saw no real difference between the proposed policy and their current practice and there was an element of trial and error in refining the policy. Respondents also 
said that early career researchers are often not the first authors of papers reporting the primary outcome of awards, and papers reporting other outcomes, in which early career researchers may be first author, are often published after the award ends and are not always financially covered by the current OA policy. These respondents questioned whether the policy would make it more difficult for early career researchers to publish OA articles.

Table 4.2. Respondents' views on the potential impacts that may occur as a result of the proposed policy principles.

\begin{tabular}{|l|l|l|l|l|l|l|}
\cline { 2 - 7 } \multicolumn{1}{l|}{} & $\begin{array}{l}\text { No } \\
\text { impact }\end{array}$ & $\begin{array}{l}\text { Only } \\
\text { positive }\end{array}$ & $\begin{array}{l}\text { Only } \\
\text { negative }\end{array}$ & $\begin{array}{l}\text { Positive } \\
\text { and } \\
\text { negative }\end{array}$ & $\begin{array}{l}\text { Don't } \\
\text { know }\end{array}$ & $\begin{array}{l}\text { No } \\
\text { opinion }\end{array}$ \\
\hline All respondents & $26(6 \%)$ & $\begin{array}{l}157 \\
(38 \%)\end{array}$ & $9(2 \%)$ & $\begin{array}{l}139 \\
(34 \%)\end{array}$ & $71(17 \%)$ & $12(3 \%)$ \\
\hline $\begin{array}{l}\text { Currently or previously } \\
\text { funded/supported by } \\
\text { the NIHR and filled out } \\
\text { by an individual, N=283 }\end{array}$ & $20(7 \%)$ & $81(29 \%)$ & $7(2 \%)$ & $\begin{array}{l}106 \\
(37 \%)\end{array}$ & $59(21 \%)$ & $10(4 \%)$ \\
\hline $\begin{array}{l}\text { Not currently or } \\
\text { previously } \\
\text { funded/supported by } \\
\text { the NIHR and filled out } \\
\text { by an individual, N=116 }\end{array}$ & $6(5 \%)$ & $76(58 \%)$ & $2(2 \%)$ & $33(25 \%)$ & $12(9 \%)$ & $2(2 \%)$ \\
\hline
\end{tabular}

Respondents were asked whether there are specific evidence user groups that the proposed policy principles would disadvantage. Overall, $86 \%(\mathrm{~N}=358 / 414)$ of respondents are not of the opinion that the proposed policy principles would disadvantage any specific evidence user groups. Of the remaining $14 \%(\mathrm{~N}=56 / 414)$, respondents suggested that the OA policy was disadvantageous for those with limited research budgets or who were seen as less likely to have access to OA funding. These included early career researchers, students, clinicians and smaller research groups and universities. Respondents identified those in specialised health areas, including the researchers and the smaller publishers of this type of work as being disadvantaged, those using less mainstream methodologies, those participating in collaborative projects, those coming from Low- and Middle-Income Countries (LMICs), and universities who had already invested in repositories as being disadvantaged by the OA policy. A few comments also indicated that the public, especially socially and economically disadvantaged people, could be disadvantaged by the OA policy, although no further explanations for these views were offered.

When asked about what additional measures the NIHR should consider to improve the accessibility and discoverability of research articles for the group(s) identified, respondents indicated that it was important to engage with stakeholder groups including industry to develop industry guidance; publishers to reach agreements that support OA, reduce article processing costs, and ensure LMICs' access to OA remains affordable; and the wider higher education sector to ensure equal access to OA funds. Alternative models to provide funds that support the costs of publishing under OA were suggested. These included funds managed centrally, using 'green' OA (depositing the AAM in a repository) or creating a new 
journal, though no details were offered as to whether this would expand or modify the publishing model of the current NIHR Journals Library.

\section{Adherence to the OA policy}

Respondents were asked for suggestions for the NIHR to drive adherence to its OA policy. Respondents suggested that NIHR needed to provide very clear guidance and communication on the OA policy. The concept of incentives and penalties were raised, with some respondents suggesting linking adherence to funding or compliance tables. There was also strong support for monitoring via reporting and auditing, through annual reports to the NIHR, or through other reporting systems such as ResearchFish or Infrastructure returns.

Respondents suggested that whatever monitoring happened needed to be simple, easy to use, flexible, and not burdensome. It was also suggested that it needed to align with other policies for ease of use and consistency. In addition, responses suggested that applicants needed to be supported in adhering to the OA policy through positive encouragement, education, advice and support. This included support through specific roles such as institutional librarians or people available to call, as well as support such as reminders, automatic deposits in Europe PMC, and lists of journals that meet the OA requirements. There was also reference to seeing how things went and if necessary, exploring the barriers to compliance, if this situation presents.

Providing researchers with sufficient time and funding to comply with the OA policy was also requested. There was also specific mention of taking publication costs out of applications and having a centralised pot of money for NIHR OA publications. Some respondents suggested making adherence to the OA policy a contractual obligation (which is already the case in the contract between DHSC and the contracting organisation that host NIHR funded research, having a disclaimer on publications to state that it met NIHR OA policy, or having an NIHR open journal where articles are published (the NIHR Journals Library's peerreviewed OA journals and NIHR Open Research platform ensure findings from NIHR funded research are publicly available). Other suggestions included putting the onus on institutions to monitor compliance and having a process to be able to report non-compliance or problems with access. Some respondents suggested that nothing specific should be done to drive adherence and instead NIHR should trust that its researchers will comply.

\section{Open Research good practice}

As part of supporting the drive for openness and transparency in research, and to ensure that researchers consider and plan for data access, the current policy requires all NIHR researchers to prepare and submit to the NIHR a statement on how underlying research materials, such as data, samples or models, can be accessed. Respondents were asked if they are aware of any open research standards or good practices that the NIHR should consider requiring in its future policies.

As shown in Figure 4.6, only $14 \%(\mathrm{~N}=59 / 414)$ of respondents were aware of such standards or practices. Respondents who reported specific examples of good open research practice cited other funders, institutions, journals, databases, archives and organisations. Although there was reference to $O A$ to research data as being an important and positive practice, some respondents warned against all research data being $O A$. These concerns linked to confidentiality and General Data Protection Regulation (GDPR) issues. Data management plans and arrangements for access to research data were discussed as necessary to support open research practices, and there was also a suggestion that research needed good statistical practice, not just data management. More general comments included the need for clear guidance on open data, consistency across all types of research (e.g., qualitative and quantitative) and the need for plain English summaries of research outputs. 


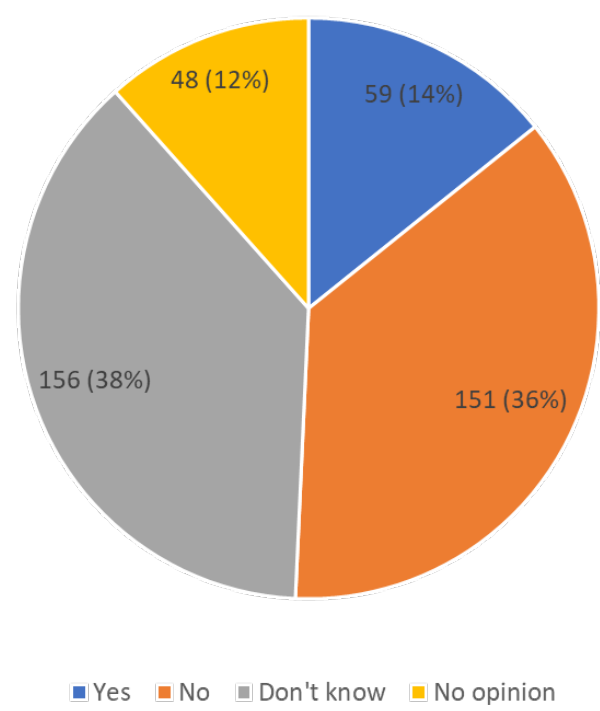

Figure 4.6. Respondents' awareness of any standards or good practices that the NIHR should consider requiring in its future open research policies.

\section{How respondents access and use research}

The survey showed that NIHR funded/supported individuals and organisations and nonNIHR funded/supported individuals used multiple methods for accessing and reading academic journal publications. The majority of respondents accessed and read academic journal publications using a university subscription or library service $(78 \%, \mathrm{~N}=312 / 399)$ or articles on the online repositories PubMed Central or Europe PMC (57\%, N = 229/399; see Table 5.1).

However, there were some nuances to this. For example, while the proportion of individuals and organisations funded/supported by the NIHR who used a university subscription or library service was $94 \%(\mathrm{~N}=267 / 283)$, only $47 \%$ of health and social care/work professionals, $20 \%$ of public contributor respondents and $8 \%$ of the general public made use of this approach to access research articles (Figure 5.2). In addition, more than half (53\%, $\mathrm{N}=17 / 32$ ) of health and social care/work professionals access articles through an NHS subscription or library service. In contrast, only $23 \%$ of individuals and organisations funded/supported by the NIHR, $18 \%$ of researchers not funded/supported by the NIHR, $8 \%$ of the general public and no public contributor respondents accessed articles in this way.

Table 5.1. How respondents access and read academic journal publications.

Type of access to academic journal publications

\begin{tabular}{|l|}
\hline $\begin{array}{l}\text { Number of } \\
\text { respondents }\end{array}$ \\
\hline $\mathrm{N}(\%)$, Total $\mathrm{N}=399$ \\
\hline
\end{tabular}




\begin{tabular}{|l|l|}
\hline $\begin{array}{l}\text { Via a university subscription or library } \\
\text { service }\end{array}$ & $312(78 \%)$ \\
\hline $\begin{array}{l}\text { Articles on PubMed Central or Europe } \\
\text { PMC }\end{array}$ & $229(57 \%)$ \\
\hline $\begin{array}{l}\text { Via journal publisher's own website or } \\
\text { platform }\end{array}$ & $144(36 \%)$ \\
\hline $\begin{array}{l}\text { Articles on a university/institutional } \\
\text { repository }\end{array}$ & $135(34 \%)$ \\
\hline Preprint repository & $81(20 \%)$ \\
\hline $\begin{array}{l}\text { Via an NHS subscription or library } \\
\text { service }\end{array}$ & $99(25 \%)$ \\
\hline Unpaywall (or equivalent) & $48(12 \%)$ \\
\hline Pay to access and read individual articles & $22(6 \%)$ \\
\hline Other & $22(6 \%)$ \\
\hline
\end{tabular}

Table 5.2. Breakdown of respondents who access and read academic journal publications via a university or NHS subscription or library service.

\begin{tabular}{|l|l|l|l|l|l|l|}
\cline { 2 - 7 } \multicolumn{1}{l|}{} & $\begin{array}{l}\text { Individuals and } \\
\text { organisations } \\
\text { funded/ } \\
\text { supported by } \\
\text { the NIHR } \\
\mathrm{N}=283\end{array}$ & $\begin{array}{l}\text { Health and } \\
\text { social } \\
\text { care/work } \\
\text { professional }\end{array}$ & $\begin{array}{l}\text { Member } \\
\text { of the } \\
\text { general } \\
\text { public }\end{array}$ & $\begin{array}{l}\text { NIHR } \\
\text { research } \\
\text { participant/ } \\
\text { public } \\
\text { contributor } \\
\mathrm{N}=32\end{array}$ & $\begin{array}{l}\text { Researcher } \\
\text { (not funded/ } \\
\text { supported } \\
\text { by the } \\
\text { NIHR) }\end{array}$ & Other \\
$\mathrm{N}=15$ & $\mathrm{~N}=22$ & 23 \\
\hline $\begin{array}{l}\text { University } \\
\text { subscription } \\
\text { or library } \\
\text { service } \\
\mathrm{N}(\%)\end{array}$ & $267(94 \%)$ & $15(47 \%)$ & $2(8 \%)$ & $3(20 \%)$ & $16(73 \%)$ & $9(39 \%)$ \\
\hline $\begin{array}{l}\text { NHS } \\
\text { subscription } \\
\text { or library } \\
\text { service } \\
\mathrm{N}(\%)\end{array}$ & $66(23 \%)$ & $17(53 \%)$ & $2(8 \%)$ & $0(0)$ & $4(18 \%)$ & $10(43 \%)$ \\
\hline
\end{tabular}

Note: These figures only report responses from NIHR funded/supported individuals and organisations and non-NIHR funded/supported individuals $(\mathrm{N}=399)$

The following information in this section reports further exploration of research use patterns of individual respondents not funded/supported by the NIHR and the type of research outputs accessed. Individuals in this group included health and social care/work professionals, members of the general public, NIHR research participants/public contributors or researchers (not funded by the NIHR), and others such as librarians or academic support staff, civil servants or employees of an arm's length body and third sector representatives. 
The survey showed that a variety of publication types were being accessed by individuals not funded/supported by the NIHR, with $87 \%$ of these respondents finding peer-reviewed primary research articles and review articles useful. (see Table 5.3).

Table 5.3. Type(s) of publications describing research findings individuals not funded/supported by the NIHR find useful.

\begin{tabular}{|l|l|l|}
\cline { 2 - 3 } \multicolumn{1}{c|}{} & $\begin{array}{l}\text { Individuals not funded/supported by } \\
\text { the NIHR }\end{array}$ \\
\cline { 2 - 3 } \multicolumn{1}{c|}{} & $\mathrm{N}=116$ & $\%$ \\
\hline Peer-reviewed primary research articles & 101 & $87 \%$ \\
\hline Review articles, including systematic reviews & 101 & $87 \%$ \\
\hline Journal editorial/comment pieces & 66 & $57 \%$ \\
\hline $\begin{array}{l}\text { NIHR communications and outputs (e.g., } \\
\text { Alerts, Collections and Themed Reviews) }\end{array}$ & 62 & $53 \%$ \\
\hline Final reports, monographs and books & 56 & $48 \%$ \\
\hline News media, blogs or social media & 57 & $25 \%$ \\
\hline Preprints & 29 & $49 \%$ \\
\hline
\end{tabular}

Of note, within this group of respondents, the pattern of findings differed for members of the general public who did not favour peer-reviewed primary research articles and review articles as strongly, also reporting using journal editorial/comment pieces, and news media, blogs or social media (see Table 5.4).

Table 5.4. Type(s) of publications describing research findings members of the general public find useful.

\begin{tabular}{|l|l|l|}
\cline { 2 - 3 } \multicolumn{1}{c|}{} & \multicolumn{2}{l|}{ Member of the general public } \\
\cline { 2 - 3 } \multicolumn{1}{c|}{} & $\mathrm{N}=24$ & $\%$ \\
\hline Peer-reviewed primary research articles & 14 & $58 \%$ \\
\hline Review articles, including systematic reviews & 14 & $58 \%$ \\
\hline Journal editorial/comment pieces & 16 & $67 \%$ \\
\hline $\begin{array}{l}\text { NIHR communications and outputs (e.g., Alerts, } \\
\text { Collections and Themed Reviews) }\end{array}$ & 15 & $63 \%$ \\
\hline Final reports, monographs and books & 8 & $33 \%$ \\
\hline News media, blogs or social media & 16 & $67 \%$ \\
\hline Preprints & 1 & $4 \%$ \\
\hline
\end{tabular}


As shown in Table 5.5, the survey showed that, on average, individuals not funded/supported by the NIHR access research articles at least once a week (57\%) or once a month $(23 \%)$.

Table 5.5. Individuals not funded/supported by the NIHR frequency of accessing research articles.

\begin{tabular}{|l|l|l|}
\cline { 2 - 3 } \multicolumn{1}{c|}{} & \multicolumn{2}{l}{$\begin{array}{l}\text { Individuals not funded/supported by } \\
\text { the NIHR }\end{array}$} \\
\cline { 2 - 3 } \multicolumn{1}{c|}{} & $\mathrm{N}=116$ & $\%$ \\
\hline At least once a week & 66 & $57 \%$ \\
\hline Once a month & 27 & $23 \%$ \\
\hline Less than once a month & 17 & $15 \%$ \\
\hline Never & 2 & $2 \%$ \\
\hline Don't Know & 4 & $3 \%$ \\
\hline
\end{tabular}

Once again, within the group of individuals not funded/supported by the NIHR, members of the general public showed a different pattern of results and reported that they are more likely to access research articles once a month (38\%) or less (38\%; See Table 5.6).

Table 5.6. Members of the public frequency of accessing research articles.

\begin{tabular}{|l|l|l|}
\cline { 2 - 3 } \multicolumn{1}{c|}{} & \multicolumn{2}{c|}{ Member of the general public } \\
\cline { 2 - 3 } \multicolumn{1}{c|}{} & $\mathrm{N}=24$ & $\%$ \\
\hline At least once a week & 4 & $17 \%$ \\
\hline Once a month & 9 & $38 \%$ \\
\hline Less than once a month & 9 & $38 \%$ \\
\hline Never & 1 & $4 \%$ \\
\hline Don't Know & 1 & $4 \%$ \\
\hline
\end{tabular}

The majority of individual respondents not funded/supported by NIHR have encountered problems accessing research articles $(N=100 / 116,86 \%)$. Respondents reported paywalls and not having organisational access (either at all or the organisational access did not encompass all journals) as the two main problems that they experienced in accessing articles. Access was also suggested to be hindered by difficulties in navigating online to find relevant articles or articles that provided lay summaries or language translations.

Respondents also commented on publisher practices, and specifically on delays and embargos on providing full access. Most of these respondents indicated that they would be 
more likely to read or use research articles if they were immediately available free of charge $(87 \%, N=101 / 116$; see Figure 5.1).

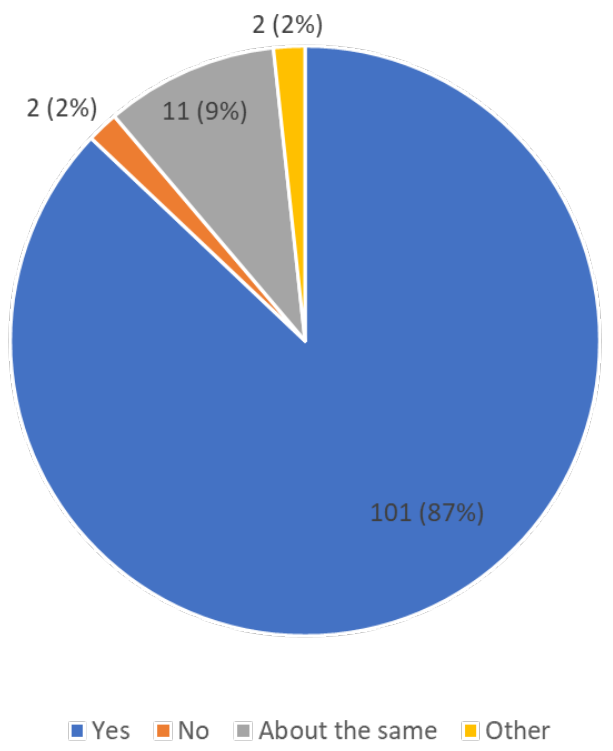

Figure 5.1. Views of respondents on whether they are more likely to read or use research articles if they were immediately available free of charge.

\section{NIHR researchers' publishing practices and reflections on the current NIHR Open Access Policy}

This section reports responses from individuals and organisations currently or previously funded/supported by the NIHR on their publishing practices and reflections on the existing NIHR OA policy. The survey showed that overall respondents had some awareness of the current NIHR OA policy (see Table 6.1), although responses ranged from no awareness to strong awareness, and only 55\% ( $N=155 / 283)$ had experience of applying the NIHR OA Policy. Of those who have experience of applying the NIHR OA policy $(\mathrm{N}=155)$, overall respondents agreed, to some extent, that the NIHR OA policy is clear and straightforward to comply with and that the NIHR provides sufficient information and guidance to enable compliance with its OA policy (see Table 6.1), although scores ranged from strongly agree to strongly disagree.

Table 6.1. Awareness and clarity of the existing NIHR OA policy.

\begin{tabular}{|l|l|l|l|l|}
\cline { 2 - 5 } \multicolumn{1}{c|}{} & Mean & Median & Min & Max \\
\hline $\begin{array}{l}\text { How aware are you of the current } \\
\text { NIHR OA policy? N }=283\end{array}$ & 3.47 & 4 & $1^{*}$ & $5^{\star}$ \\
\hline $\begin{array}{l}\text { The NIHR OA policy is clear and } \\
\text { straightforward to comply with. N } \\
=155\end{array}$ & 3.47 & 4 & $1^{\wedge}$ & $5^{\wedge}$ \\
\hline
\end{tabular}




\begin{tabular}{|l|l|l|l|l|}
\hline $\begin{array}{l}\text { The NIHR provides me with } \\
\text { sufficient information and } \\
\text { guidance to enable me to comply } \\
\text { with its OA policy. } \mathrm{N}=155\end{array}$ & 3.52 & 4 & $1^{\wedge}$ & $5^{\wedge}$ \\
\hline
\end{tabular}

*1= no awareness, 5 = strong awareness; ${ }^{\wedge} 1=$ strongly disagree, 5 = strongly agree

The survey showed that $28 \%(\mathrm{~N}=80 / 283)$ of respondents reported that all of their published NIHR-funded research articles were immediately OA and $32 \%(\mathrm{~N}=91 / 283)$ reported that a majority of their published NIHR-funded research articles were immediately OA (see Figure 6.1). Only $8 \%(\mathrm{~N}=22 / 283)$ of respondents reported that none of their NIHR-funded research articles published in the past five years were immediately OA.

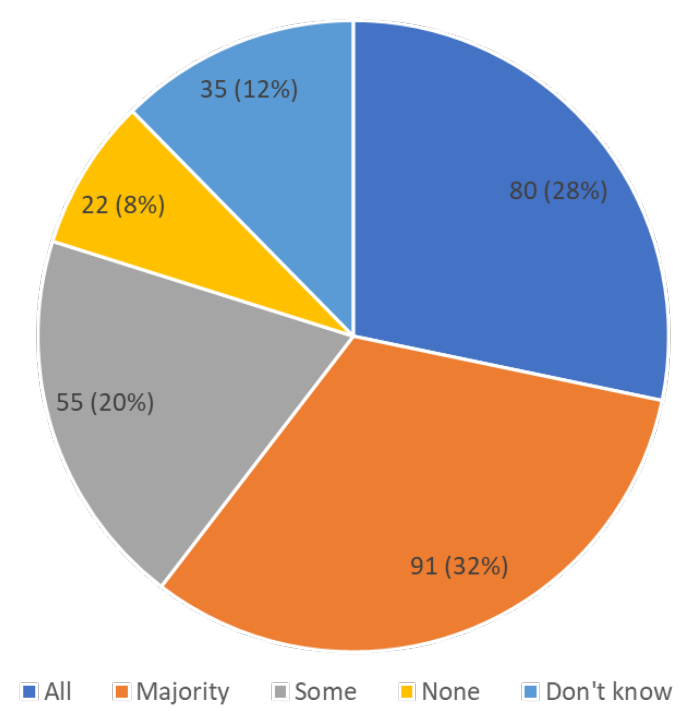

Figure 6.1. Proportion of NIHR-funded research articles that respondents reported to have published OA in the past five years.

Respondents reported the main barrier to publishing research immediately OA was funding. This was in relation to a lack of research funds available for OA costs on all publications, articles published after a funding award has ended, as well as the institutional processes involved in making article processing payments.

Respondents also reported a lack of experience or awareness of OA and the current NIHR OA policy, which linked to concerns and confusion on copyright and collaboration (e.g., different institutional policies). Barriers also included discoverability (with institutional repositories being more difficult to search) and the desire to publish in specific journals sometimes being greater than the consideration of whether the journal publishes under OA.

The majority of respondents felt that the way the NIHR currently supports the costs of its OA policy by funding publication charges as part of award applications was suitable with some difficulties ( $N=147 / 283,52 \%)$, but only $31 \%$ said it was suitable $(N=88 / 283$ see Figure 6.2$)$. Support from the NIHR for OA publishing was acknowledged and welcomed, though some comments indicated that not all the research community is aware of the support that is available. In addition, respondents commented that there were difficulties in predicting the full costs of OA publications at the time of application, which combined with the variable (but 
high) article processing charges of journals in different fields, and articles being published after awards end, can lead to insufficient funds during and after a research award to publish all outputs of a project under an OA policy. Some respondents suggested alternative funding models such as block and central funding to address the issue of difficulties in planning for publications at the application stage. Some respondents felt that OA was expensive and did not always bring value for money.

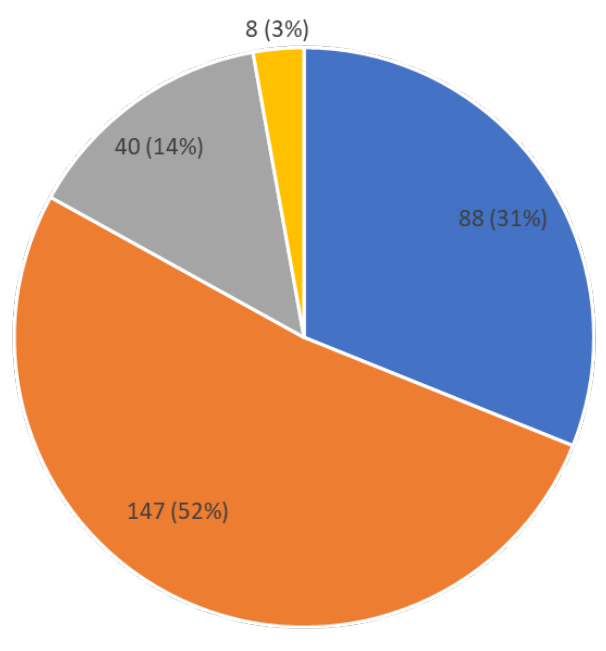

¿ Suitable $\square$ Suitable with some difficulties $\square$ Not suitable at all $\square$ Don't know

Figure 6.2. Views of respondents on the current NIHR OA funding approach.

Respondents reported that they did not often publish NIHR funded research findings as preprints or, with the exception of NIHR Journals Library, in monographs, book chapters or edited collections (see Figure 6.3). In addition, nearly half did not know whether NIHRfunded research articles published in the past five years were deposited into Europe PMC (see Figure 6.4). Respondents cited hinderances to depositing articles into Europe PMC, including lack of awareness of NIHR deposit requirements; lack of clarity on who was responsible for depositing articles into Europe PMC, with some respondents stating that they assumed it was automatic or that others (e.g., institutional librarians, publishers) did this for them; administrative burden; lack of understanding of how to deposit articles into Europe PMC; and concerns around potential conflicting publisher and institutional deposit policies. 

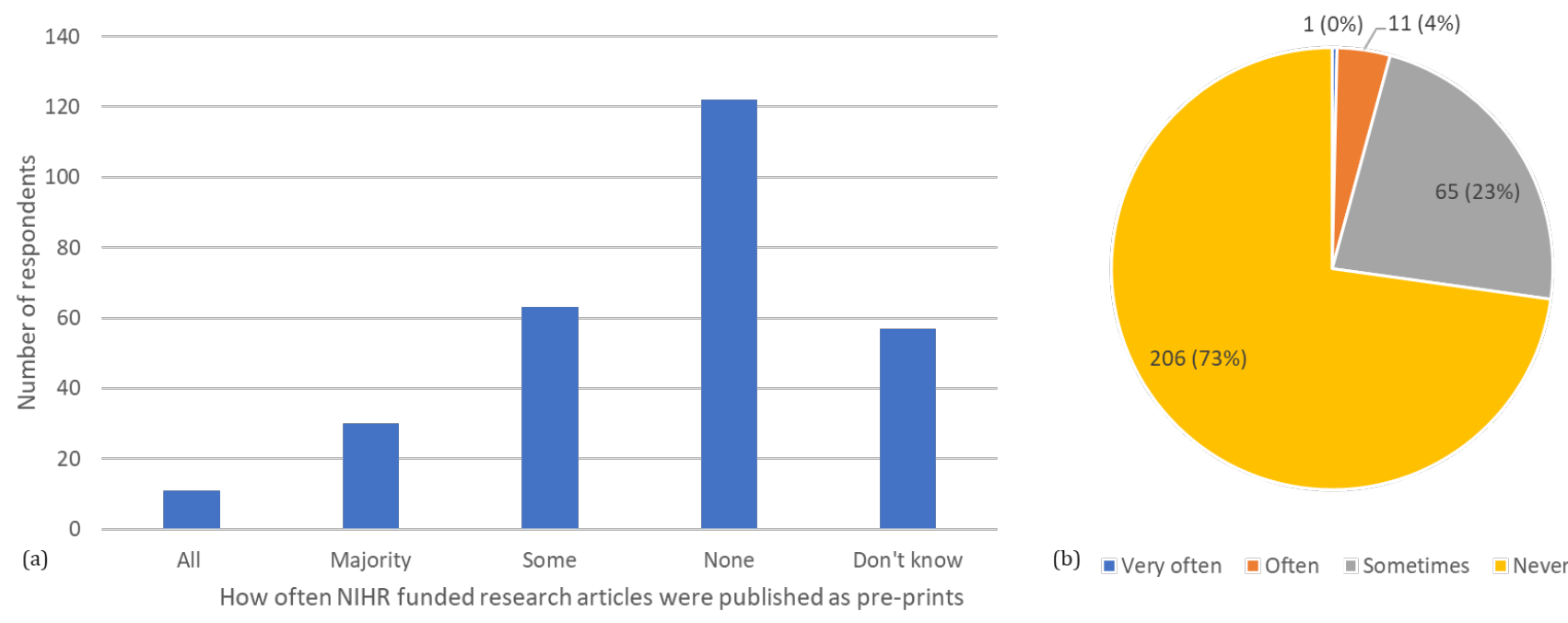

Figure 6.3. (a) Number of NIHR-funded research articles that respondents reported to be originally published as pre-prints in the past five years. (b) Proportion of NIHR-funded research that respondents reported to have published as monographs, book chapters or edited collections.

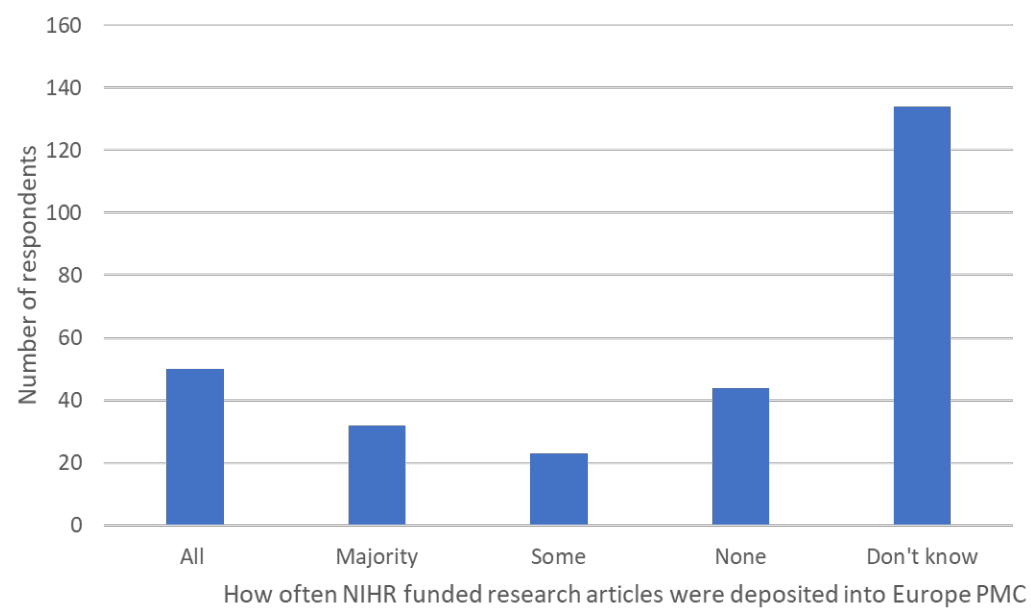

Figure 6.4. Number of NIHR-funded research articles that respondents reported to be originally deposited into Europe PMC in the past five years.

The survey showed that $59 \%(\mathrm{~N}=166 / 283)$ of respondents had some experience of other research funders' OA policies (see Table 6.2), and 14\% ( $\mathrm{N}=41 / 283)$ had experienced difficulties trying to comply with the OA policies of more than one research funder for cofunded awards. Difficulties in complying with the OA policies of more than one research funder included a lack of clarity in how to resolve conflicting or different requirements of different OA policies, a lack of awareness of OA journals and access to OA funds, high costs of OA publishing, and confusion over perceived restrictions on publications which describe findings reported in funder reports. 
Table 6.2. Respondents with experience of other (non-NIHR) research funders' OA policies.

\begin{tabular}{|l|l|}
\hline Research funder & $\begin{array}{l}\text { Number of } \\
\text { respondents } \\
\mathbf{N}=\mathbf{2 8 3}(\%)\end{array}$ \\
\hline UK Research and Innovation (UKRI) & $83(29 \%)$ \\
\hline Wellcome Trust & $64(23 \%)$ \\
\hline Charity & $79(28 \%)$ \\
\hline Department for International Development (DFID) & $7(2 \%)$ \\
\hline $\begin{array}{l}\text { EU framework programmes (e.g., Horizon 2020, } \\
\text { FP7) }\end{array}$ & $25(9 \%)$ \\
\hline Industry & $11(4 \%)$ \\
\hline European Research Council (ERC) & $10(4 \%)$ \\
\hline Other & $10(4 \%)$ \\
\hline None & $117(41 \%)$ \\
\hline
\end{tabular}




\section{Scope}

In scope: Our policy exploration is based on a scope that includes peer-reviewed research articles (the final version of record or the author's accepted manuscript) that result from a majority NIHR funded project. The scope includes primary research articles, review articles not commissioned by publishers, final reports or executive summaries.

Out of scope: Monographs (with the exception of NIHR Journals Library publications), book chapters, edited collections, or forms of non-peer-reviewed material, such as pre-prints, are considered out of scope of this policy.

Timing of implementation: We propose that the new NIHR OA policy will apply to NIHR awards which begin on or after 1 April 2022. In considering when the policy might apply, we are seeking to balance advancing full and immediate access to the research NIHR funds with providing adequate time for stakeholders to adapt to a new policy.

\section{Policy principles}

Principle 1 - publications must be accessible and open immediately.

All in scope publications must be available online as soon as they are published, without any embargo period.

\section{Principle 2 - there should be no barriers to the re-use and dissemination of NIHR publications.}

All publications should be published under the Creative Commons attribution licence (CC$B Y$ ), or Open Government Licence (OGL) to ensure maximum impact. This will permit all users of NIHR funded publications to disseminate and build upon the material for any purpose without further permission or fees being required.

\section{Principle 3 - publications must be freely discoverable.}

All publications should be freely discoverable to those that may wish to research, share and use the outcomes of our published research, including patients, service users, carers and the public. This includes machine readability and accessibility to ensure full utility of NIHR publications.

\section{Principle 4 - NIHR will pay reasonable fees.}

When an OA payment is applicable, for example an Article Processing Charge (APC), we will pay reasonable fees required by a publisher to effect publication in line with the criteria of this policy for all in scope publications expected to stem from an NIHR award. 